\title{
Different Clusters in Patients with Chronic Obstructive Pulmonary Disease (COPD): A Two-Center Study in Brazil
}

This article was published in the following Dove Press journal: International Journal of Chronic Obstructive Pulmonary Disease

\author{
José William Zucchi ${ }^{1}$ \\ Estefânia Aparecida Thomé \\ Franco (D) \\ Thomas Schreck $\mathbb{D}^{2}$ \\ Maria Helena Castro e Silva (D) $^{3}$ \\ Sandro Rogerio dos Santos \\ Migliorini (iD $)^{3}$ \\ Thaís Garcia' \\ Gustavo Augusto Ferreira Mota' \\ Bruna Evelyn Bueno de Morais (D) \\ Luiz Henrique Soares Machado' \\ Ana Natália Ribeiro Batista' \\ Sergio Alberto Rupp de Paiva (ID) \\ Irma de Godoy' \\ Suzana Erico Tanni (DD' \\ 'Pulmonology Division of Botucatu \\ Medical School, São Paulo State \\ University (UNESP), Botucatu, Brazil; \\ ${ }^{2}$ Ostbayerische Technische Hochschule \\ Regensburg (OTH Regensburg), Faculty \\ of Business Studies, Regensburg, German; \\ ${ }^{3}$ Pulmonology Division of Federal \\ University of Triângulo Mineiro, Uberaba, \\ Brazil
}

Correspondence: José William Zucchi Email jwzucchi@hotmail.com
Background: Chronic obstructive pulmonary disease (COPD) has a functional definition. However, differences in clinical characteristics and systemic manifestations make COPD a heterogeneous disease and some manifestations have been associated with different risks of acute exacerbations, hospitalizations, and death.

Objective: Therefore, the objective of the study was to evaluate possible clinical clusters in COPD at two study centers in Brazil and identify the associated exacerbation and mortality rate during 1 year of follow-up.

Methods: We included patients with COPD and all underwent an evaluation composed of the Charlson Index, body mass index (BMI), current pharmacological treatment, smoking history (packs-year), history of exacerbations/hospitalizations in the last year, spirometry, six-minute walking test (6MWT), quality of life questionnaires, dyspnea, and hospital anxiety and depression scale. Blood samples were also collected for measurements of C-reactive protein (CRP), blood gases, laboratory analysis, and blood count. For the construction of the clusters, 13 continuous variables of clinical importance were considered: hematocrit, CRP, triglycerides, low density lipoprotein, absolute number of peripheral eosinophils, age, pulse oximetry, BMI, forced expiratory volume in the first second, dyspnea, 6MWD, total score of the Saint George Respiratory Questionnaire and packs-year of smoking. We used the Ward and K-means methods and determined the best silhouette value to identify similarities of individuals within the cluster (cohesion) in relation to the other clusters (separation). The number of clusters was determined by the heterogeneity values of the cluster, which in this case was determined as four clusters.

Results: We evaluated 301 COPD patients and identified four different groups of COPD patients. The first cluster (203 patients) was characterized by fewer symptoms and lower functional severity of the disease, the second cluster by higher values of peripheral eosinophils, the third cluster by more systemic inflammation and the fourth cluster by greater obstructive severity and worse gas exchange. Cluster 2 had an average of $959 \pm 3$ peripheral eosinophils, cluster 3 had a higher prevalence of nutritional depletion (46.1\%), and cluster 4 had a higher BODE index. Regarding the associated comorbidities, we found that only obstructive sleep apnea syndrome and pulmonary thromboembolism were more prevalent in cluster 4 . Almost $50 \%$ of all patients presented an exacerbation during 1 year of follow-up. However, it was higher in cluster 4 , with $65 \%$ of all patients having at least one exacerbation. The mortality rate was statistically higher in cluster 4 , with $26.9 \%$, vs $9.6 \%$ in cluster 1 .

Conclusion: We could identify four clinical different clusters in these COPD populations, that were related to different clinical manifestations, comorbidities, exacerbation, and mortality rate. We also identified a specific cluster with higher values of peripheral eosinophils.

Keywords: COPD, eosinophils, cluster analysis, COPD phenotype, lung function 


\section{Introduction}

Chronic obstructive pulmonary disease (COPD) has a precise functional definition. Conversely, variations in systemic and clinical characteristics occur in COPD patients and may directly influence clinical outcomes. ${ }^{1}$ These characteristics are related to different comorbidities, such as cardiovascular, metabolic diseases; osteoporosis; nutritional, hematological and psychological factors; and inflammatory process, which contribute to increased risk of acute exacerbations, hospitalization, and death..$^{2-4}$.

The high prevalence of comorbidities and the complexity of COPD mean that alternative tools can be used to assess the severity of the disease. ${ }^{5-7}$ The severity of airway obstruction, the presence of nutritional depletion, physical capacity, and the magnitude of dyspnea are variables that stratify a possible higher risk group. ${ }^{8}$ However, it is necessary to identify the varied markers associated with different clinical outcomes to define phenotypes of COPD.$^{8-10}$

In this context, previous studies have shown that COPD phenotypes depend on the characteristics of the population evaluated, ${ }^{11,12}$ such as smoking history, respiratory symptoms, comorbidities, pulmonary function test, exercise capacity, and inflammatory biomarkers. ${ }^{12,13}$ One study identified a group of COPD phenotype in elderly patients with severe airflow limitation, high nutritional depletion, muscle weakness, acute COPD exacerbations, and osteoporosis. ${ }^{9}$ Another phenotype group included young female patients with severe COPD, frequent exacerbations, and increased hospitalization. ${ }^{15,14} \mathrm{~A}$ further phenotype described in the literature refers to patients with low exercise capacity and worse dyspnea symptom with a higher prevalence of comorbidities and worse prognosis of survival. ${ }^{16}$

Inclusion of inflammatory biomarkers of COPD to accurately phenotype is extremely important to better understand and to identify COPD patients with higher risk of exacerbation and death. ${ }^{17,18}$ New evidence suggests that serum eosinophil levels may be related to disease exacerbation risk and treatment response. ${ }^{19-21}$ This population associated with exacerbation history characterize a distinct group in COPD. However, there are few data that have evaluated the influence of serum eosinophil levels in cluster analysis to determine different COPD phenotypes. ${ }^{22,23}$

Therefore, the aim of the present study was to evaluate possible clinical clusters including serum eosinophils in COPD patients that can be associated with different prevalence of exacerbation, hospitalization, and mortality.

\section{Subjects}

This is a longitudinal observational study conducted in two study centers in Brazil, from August 2016 to October 2018. A total of 334 consecutive subjects were evaluated, 301 subjects from the Clinic Hospital of Botucatu Medical School, and 33 subjects from the Federal University of Uberaba-Minas Triangle. Inclusion criteria were subjects greater than 40 years old, all COPD severities (1-4 and A-D) according to GOLD 2017 classification, outpatient clinically stable patients characterized by the absence of acute exacerbation, and regular use of drugs for treatment in the preceding 4 weeks, cigarette consumption of more than 10 packs per year, and/or exposure to biomass, and who agreed to participate in the study protocol. Exclusion criteria were patients who had used systemic corticosteroids in the preceding 4 weeks or who had bronchiectasis, active tuberculosis, or malignant neoplasia.

All subjects signed the informed consent form approved by the Research Ethics Committee under opinion number 1399669 and CAAE: 52515215.2.1001.5411 and approved by the Brazilian Registry of Clinical Trials (REBEC) under the registration RBR-5B6B6S. This study was conducted in accordance with the Declaration of Helsinki.

\section{Study Design and Methods}

All project procedures were performed on the same day baseline and included demographic characteristics (age, gender, occupation, education, and monthly income), smoking history (packs/year calculation and active or non-active smoking), presence of history of exposure to biomass, pulse oximeter $\left(\mathrm{SpO}_{2}\right)$, and body mass index (BMI) calculation. The six-minute walk test was performed according to the American Thoracic Society guidelines. ${ }^{24}$

The diagnosis of COPD was made by post bronchodilator spirometry [Forced Expiratory Volume in $1 \mathrm{Second} /$ Forced Vital Capacity (FEV1/FVC $<0.70$ ), and classified by FEV1 according to criteria of the Global Initiative for Chronic Obstructive Lung Disease $2017^{25}$ and the Brazilian Thoracic Society]. ${ }^{26}$ Spirometry was performed on a portable computerized pulmonary function system (Ferraris Koko, Louisville, CO, USA), according to the criteria of the American Thoracic Society. FVC in liters (L) and FEV1 in liters (L) were measured, and the ratio between the two measures (FEV1/FVC) was calculated. The measurements were obtained before and 20 minutes after the use of $400 \mathrm{mcg}$ metered dose fenoterol as a bronchodilator medication. The 
FVC and FEV1 values were also expressed as a percentage of the reference values.

Specific pharmacological treatment for COPD (corticosteroids, bronchodilators, anti-inflammatory drugs, immunomodulators, and oxygen), duration of use, participation in pulmonary rehabilitation, and vaccine status were evaluated.

The Charlson ${ }^{38}$ index was used to evaluate comorbidities and the Saint George Respiratory Questionnaire $(\mathrm{SGRQ})^{27}$ and COPD Assessment Test-CAT ${ }^{28}$ were applied to assess quality-of-life. The hospital anxiety and depression scale (HAD) was applied to identify anxiety and depression symptoms. ${ }^{29,30}$ The dyspnea score was evaluated by Basal Dyspnea Index (BDI $)^{31}$ and Modified Medical Research Council (MMRC), ${ }^{26}$ and the BODE multidimensional index was calculated for COPD. ${ }^{32}$

Arterial gases were collected by puncture of the radial artery, with the patient at rest and breathing ambient air. The patient also fasted for 8 hours to assess glucose, C-reactive protein (CRP), cholesterol, and fractions and triglycerides (TG) biochemical laboratory analysis and complete blood count (Stat Profile 5 Plus - Nova Biomedical, Waltham, MA, USA). We considered positive diabetes mellitus and dyslipidemia according to the Brazilian Diabetes Society ${ }^{33}$ and Brazilian Cardiologic Society. ${ }^{34}$

All patients were followed for 4 months during 1 year to assess the rate of COPD acute exacerbation, hospitalization, and death. Acute exacerbation was considered when the patient presented an acute worsening in the baseline dyspnea, cough, and/or sputum with a necessity to change the regular medication with adding corticosteroids and/or antibiotics. ${ }^{25}$ We used medical records and patient's prescription to validate this information. In the case of death, the causality was recorded by medical records and/or official documentation of the causality of death.

\section{Statistical Analysis}

The sample size calculation was considered a previous pilot study conducted in our center. Six different clusters were identified, and a 300 COPD-subject size sample was calculated based on multiple comparison analysis. Sample size calculation was based on analysis of variance (ANOVA), with mean difference between groups in 6MWT $(54 \pm 105 \mathrm{~m})$, with $80 \%$ of power and two-sided $P$-value $=0.0033$, and a hypothetical loss rate of $30 \%$.

Descriptive data analysis was performed to describe the characteristics of all participants. Continuous variables are presented as mean \pm standard deviation (SD) or as medians and percentiles (25-75), and categorical variables are expressed as a percentage. ANOVA test followed by the Tukey's test or Kruskal Wallis test followed by Dun's test were used to compare the pairs according to variable distribution. The chi-squared test was used to compare categorical variables.

For the construction of clusters, 13 continuous variables with clinical importance were considered: hematocrit (HT), CRP, TG, low density lipoprotein (LDL), absolute peripheral eosinophils number, age, $\mathrm{SpO}_{2}, \mathrm{BMI}, \mathrm{FEV1}$, BDI, 6MWD, total score of SGRQ, and smoking-year package. We use the Ward and K-means methods and we determined the best silhouette value to identify similarities of individuals within the cluster (cohesion) in relation to the other clusters (separation). Given the statistical results for the Ward and $\mathrm{K}$ means method, the variables CRP, absolute eosinophils, and $\mathrm{SpO}_{2}$ were chosen because they present the best silhouette value and were considered in the analysis of the main components. After choosing the best cluster construction method for the silhouette value (Ward method), the best cluster number (three or four) was determined through the heterogeneity values of the clusters, which in this case was four clusters.

The number of clusters was determined by the cluster heterogeneity values, which in this case was four clusters. The evaluation of each patient was performed to determine the belonging group. Among these, 10 patients were not assigned into cluster analysis related to missing data, and were excluded from the pairwise comparison.

All analyzed variables were performed with the significance level set at $P<0.05$, with the statistical package IBM SPSS Statistics 22 (TX-USA).

\section{Results}

After reviewing all evaluated subjects, 301 COPD patients were included, and the flow chart is presented in Figure 1. The present study identified four different clusters in this sample of COPD patients. The proportions of pharmacological treatment according to each cluster are presented in Figure 2. The long-acting beta 2 agonist was the pharmacological treatment used in all clusters, followed by long-acting anticholinergic and inhaled corticosteroids. We did not observe a statistical difference between groups according to the proportion of pulmonary rehabilitation and vaccine use. In terms of the proportion of previous exacerbation before the baseline assessment, we identified in clusters $14,-33.5 \%$, $34 \%, 30 \%$, and $38.5 \%$, respectively $(P=0.70)$. 


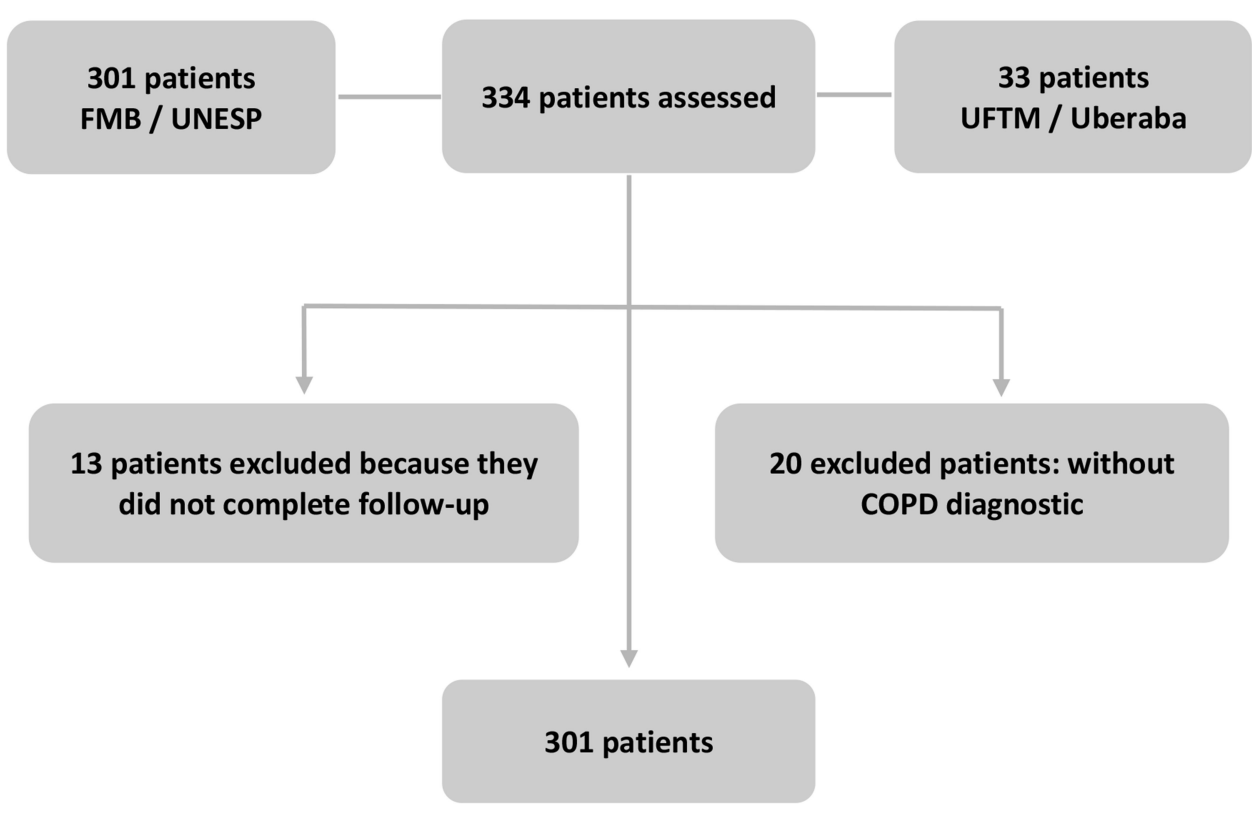

Figure I Total patient evaluation, division of each study center, inclusion and exclusion criteria, and final number of patients evaluated.

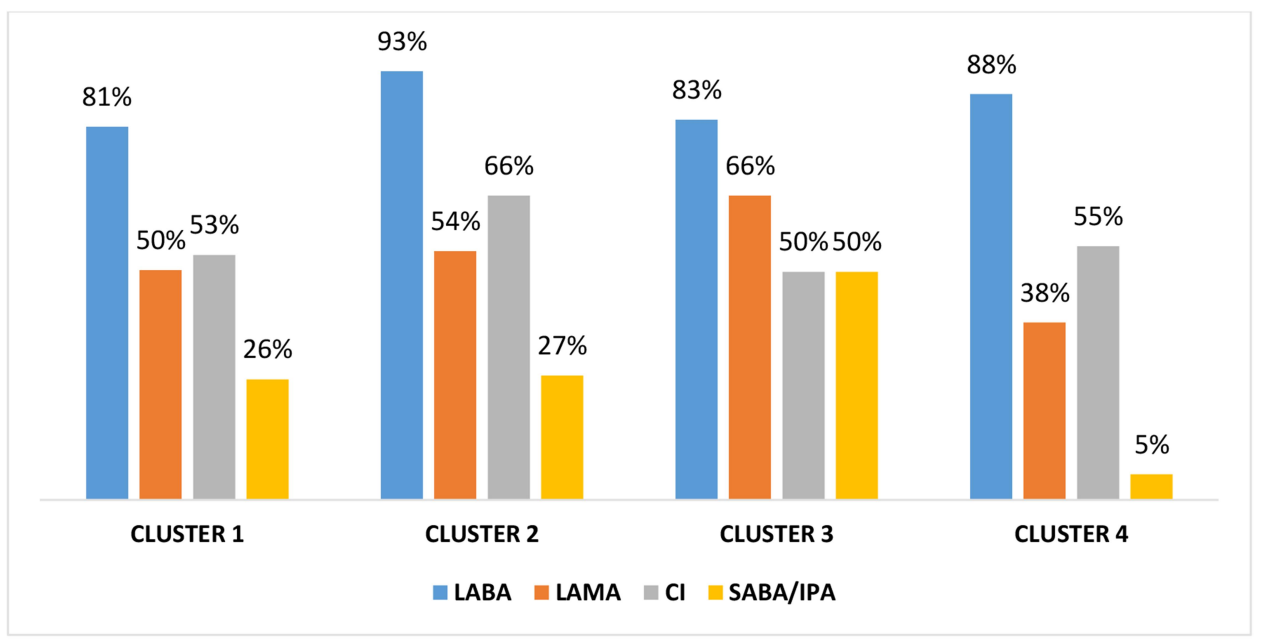

Figure 2 Proportions of pharmacological treatment according to each cluster. Values expressed as a percentage.

Abbreviations: LABA, long-acting beta2-agonists; LAMA, long-acting anticholinergic; $\mathrm{Cl}$, inhaled corticosteroids; SABA/IPA, short-acting beta agonists/short-acting anticholinergics.

When all the groups were compared, the first group included the largest number of patients in the sample (203 patients) and had lower severity of the disease, characterized by lower values of the BODE index when compared to cluster $4(P=0.035)$. This cluster also presented one of the longest distances in the 6MWD and had the lowest score of dyspnea when compared to cluster $4(P=0.048)$ (Table 1).

The second cluster (49 patients) had higher peripheral eosinophil values, with a mean of $959 \pm 389 \times 10^{3} / \mathrm{mm}^{3}$. However, only four patients had asthma diagnosis and only $34 \%$ presented a history of previous exacerbations in the year before baseline assessment. They also presented higher values of lymphocytes $\left(2084 \pm 737103 / \mathrm{mm}^{3}\right)$ when compared to cluster $4(P=0.005)$ (Table 1$)$.

Cluster 3 had a male predominance $(69.2 \%)$ and we observed higher systemic inflammation by CRP concentration $(6.1 ; 4.1-7.7 \mathrm{~mL})$ compared to other clusters $(P<0.0001)$. The evaluation of body composition in cluster 3 presented a higher proportion of depletion $\left(22.6 \pm 6.1 \mathrm{~kg} / \mathrm{m}^{2}\right)$, with $46.1 \%$ of patients with BMI below $21 \mathrm{~kg} / \mathrm{m}^{2}$. Absolute peripheral neutrophil cells were higher in cluster $3\left(6535 \pm 2587103 / \mathrm{mm}^{3}\right)$ 
Table I General Characteristics of the Patients According to Cluster

\begin{tabular}{|c|c|c|c|c|c|}
\hline \multicolumn{6}{|l|}{ Cluster } \\
\hline Variables & $I(n=203)$ & $2(n=49)$ & $3(n=13)$ & $4(n=26)$ & $P$-value \\
\hline Age, years & $67.3 \pm 9.4$ & $68.0 \pm 10.5$ & $67.5 \pm 9.7$ & $68.1 \pm 10.0$ & 0.95 \\
\hline Male, \% & 52.7 & 59.1 & 69.2 & 42.3 & 0.34 \\
\hline BMI, $\mathrm{kg} / \mathrm{m}^{2}$ & $25.9 \pm 5.6^{\mathrm{a}, \mathrm{b}}$ & $24.2 \pm 5.5^{b}$ & $22.6 \pm 6.1^{\mathrm{b}}$ & $28.9 \pm 6.4^{\mathrm{a}}$ & 0.002 \\
\hline $\mathrm{SpO}_{2}$ rest, $\%$ & $93.0 \pm 2.6^{\mathrm{b}}$ & $92.0 \pm 3.2^{\mathrm{b}}$ & $92.8 \pm 2.82^{\mathrm{b}}$ & $80.6 \pm 5.0^{\mathrm{a}}$ & $<0.0001$ \\
\hline $\mathrm{SaO}_{2}, \mathrm{mmHg}$ & $90.3 \pm 7.6$ & $90.4 \pm 9.5$ & $86.3 \pm 10.8$ & $89.2 \pm 5.7$ & 0.38 \\
\hline $\mathrm{PaO}_{2}, \mathrm{mmHg}$ & $64.9 \pm 22.9$ & $66.6 \pm 11.4$ & $57.9 \pm 15.3$ & $61.3 \pm 12.8$ & 0.06 \\
\hline $\mathrm{PaCO}_{2}, \mathrm{mmHg}$ & $41.2 \pm 6.9$ & $40.2 \pm 7.1$ & $43.7 \pm 8.2$ & $42.0 \pm 7.1$ & 0.52 \\
\hline Neutrophils, $10^{3} / \mathrm{mm}^{3}$ & $4649 \pm 1658^{a}$ & $5116 \pm|7| 2^{\mathrm{a}, \mathrm{b}}$ & $6535 \pm 2587^{b}$ & $5215 \pm 2194^{\mathrm{a}, \mathrm{b}}$ & 0.002 \\
\hline Eosinophils, $10^{3} / \mathrm{mm}^{3}$ & $218 \pm 103^{b}$ & $959 \pm 389^{\mathrm{a}}$ & $221 \pm 159^{b}$ & $236 \pm 140^{b}$ & $<0.0001$ \\
\hline Lymphocytes, $10^{3} / \mathrm{mm}^{3}$ & $1858 \pm 638^{\mathrm{a}, \mathrm{b}}$ & $2084 \pm 737^{\mathrm{a}}$ & $1707 \pm 577^{\mathrm{a}, \mathrm{b}}$ & $|56| \pm 547^{b}$ & 0.008 \\
\hline CRP, mg/dL & $0.7(0.5-1.2)^{\mathrm{a}, \mathrm{c}}$ & $0.6(0.5-1.2)^{\mathrm{a}, \mathrm{c}}$ & $6.1(4.1-7.7)^{b}$ & I. $4(0.7-2.0)^{\mathrm{a}, \mathrm{c}}$ & $<0.0001$ \\
\hline Previous exacerbation rate, $\%$ & 33.5 & 34 & 30 & 38.5 & 0.70 \\
\hline Exacerbation I year of follow-up, \% & 47 & 55 & 61 & 65 & 0.27 \\
\hline FVC, L & $2.36 \pm 0.8$ & $2.29 \pm 0.8$ & $2.29 \pm 0.4$ & $1.89 \pm 0.7$ & 0.07 \\
\hline $\mathrm{FCV}, \%$ & $69.7 \pm 20.6$ & $66.3 \pm 15.5$ & $68.0 \pm 15.1$ & $60.2 \pm 15.1$ & 0.14 \\
\hline $\mathrm{FEV}_{\mathrm{I}}, \mathrm{L}$ & $1.25 \pm 0.6$ & $1.17 \pm 0.5$ & $1.07 \pm 0.3$ & $0.98 \pm 0.4$ & 0.09 \\
\hline $\mathrm{FEV}_{1}, \%$ & $46.9 \pm 18.4$ & $43.1 \pm 12.9$ & $42.2 \pm 16.6$ & $40.0 \pm 21.5$ & 0.18 \\
\hline $\mathrm{FEV} / \mathrm{FCV}, \mathrm{L}$ & $0.52 \pm 0.0$ & $0.5 I \pm 0.0$ & $0.48 \pm 0.1$ & $0.5 I \pm 0.0$ & 0.43 \\
\hline Pulmonary rehabilitation, $\%$ & 6.4 & 4.0 & 0.0 & 7.7 & 0.71 \\
\hline Vaccines & $55.6 \%$ & $67.3 \%$ & $46.1 \%$ & $53.8 \%$ & 0.38 \\
\hline 6MWD, m & $412.4 \pm 118.0^{b, c}$ & $433.3 \pm 88.9^{b}$ & $320.6 \pm 104.3^{\mathrm{a}}$ & $350.1 \pm 119.4^{\mathrm{a}, \mathrm{c}}$ & 0.002 \\
\hline MMRC & $1.1 \pm 1.1^{\mathrm{a}}$ & $1.9 \pm 1.1^{\mathrm{a}, \mathrm{b}}$ & $2.3 \pm 0.9^{\mathrm{a}, \mathrm{b}}$ & $2.4 \pm 1.1^{\mathrm{b}}$ & 0.033 \\
\hline BDI & $6.5 \pm 2.6$ & $6.2 \pm 2.3$ & $6.2 \pm 2.4$ & $5.3 \pm 2.2$ & 0.18 \\
\hline CAT & $15.5 \pm 8 . \mid$ & $16.0 \pm 8.5$ & $18.1 \pm 4.0$ & $17.2 \pm 8.8$ & 0.60 \\
\hline SGRQ, Total\% & $45.3 \pm 19.8$ & $42.9 \pm 17.7$ & $50.9 \pm 21.4$ & $46.2 \pm 18.2$ & 0.60 \\
\hline Packs-year & $61.5 \pm 40.8$ & $50.4 \pm 27.8$ & $66.0 \pm 35.7$ & $62.5 \pm 38.9$ & 0.29 \\
\hline LTOT,\% & 22.2 & 32.6 & 30.0 & 76.9 & $<0.0001$ \\
\hline Anxiety scale & $6.4 \pm 4.3$ & $6.8 \pm 5.2$ & $6.8 \pm 6.7$ & $5.2 \pm 2.8$ & 0.47 \\
\hline Depression scale & $5.4 \pm 4.6$ & $5.2 \pm 5.0$ & $5.2 \pm 4.2$ & $2.9 \pm 3.0$ & 0.80 \\
\hline Charlson Index & $4.3 \pm 1.6$ & $4.6 \pm 1.7$ & $4.5 \pm 1.4$ & 4. 1.4 & 0.58 \\
\hline BODE Index & $2.4 \pm 1.7^{\mathrm{a}}$ & $2.5 \pm 1.4^{\mathrm{a}, \mathrm{b}}$ & $3.5 \pm 1.8^{\mathrm{a}, \mathrm{b}}$ & $3.4 \pm 1.8^{\mathrm{b}}$ & 0.01 \\
\hline $\mathrm{SAH}, \%$ & 57.7 & 63.0 & 53.8 & 65.3 & 0.79 \\
\hline DM, \% & 24.8 & 23.9 & 7.6 & 19.2 & 0.51 \\
\hline DLP, \% & 29.4 & 32.6 & 7.6 & 11.5 & 0.07 \\
\hline OSAS, \% & 2.4 & 0 & 0 & 11.5 & 0.03 \\
\hline
\end{tabular}

Notes: Values expressed as mean \pm standard deviation or percentage. Reviewed by $\chi^{2}$, ANOVA followed by Tukey's test. Different letters indicate statistical difference with $P P<0.05$.

Abbreviations: $\mathrm{BMI}$, body mass index; $\mathrm{SpO}_{2}$, peripheral oxygen saturation; CRP, C-reactive protein; FVC, forced vital capacity; $\mathrm{FEV}$, forced expiratory volume in the first second; $F E V_{1} / F C V$, ratio between forced expiratory volume in the first second and forced vital capacity; Vaccines, pneumococcal vaccine and influenza vaccine; $6 M W D$, distance covered in the six-minute walk test in meters; MMRC, Medical Research Council modified Dyspnea Scale; BDI, Baseline Dyspnea Index; CAT, COPD Assessment Test; SGRQ, Saint George Respiratory Questionnaire; LTOT, long-term oxygen therapy; SAH, systemic arterial hypertension; DM, diabetes mellitus; DLP, dyslipidemia OSAS, obstructive sleep apnea syndrome.

when compared to cluster $1(P=0.002)$. The $6 \mathrm{MWT}$ was a lower value $(320.6 \pm 104.3 \mathrm{~m})$ in cluster 3 when compared to cluster $1(412.4 \pm 118.0 \mathrm{~m})$ and cluster $2(433.3 \pm 88.9 \mathrm{~m})$ $(P=0.002)$.

The last cluster was characterized by patients with higher COPD severity (FEV1: 40.0 $\pm 21.5 \%$ ), with lower $\mathrm{SpO}_{2}$ values $(80.6 \pm 5.0 \%)$, and the proportion of patients using long-term oxygen therapy was statistically significant $(76.9 \% ; P<0.0001)$. BMI mean value was higher in this group $\left(28.9 \pm 6.4 \mathrm{~kg} / \mathrm{m}^{2}\right)$ when compared to clusters $2(P=0.005)$ and $3(P=0.007)$, and the presence of obstructive sleep apnea and thromboembolism was higher in this group.

No statistical differences were identified between groups according to the prevalence of other different comorbidities, CAT, and HAD scores. 
After 1 year of follow-up, we observed that more than $50 \%$ of all patients presented one exacerbation in each cluster in 1 year of follow-up. The exacerbation rate was higher in cluster 4 , with a $65 \%$ proportion of all patients with at least one exacerbation (Figure 3). The hospitalization rate in all patients was $53 \%$, without differences between clusters. The mortality rate was statistically different between groups $(P=0.035)$, a higher rate was observed in cluster 4 , with $26.9 \%$ vs $9.6 \%$ in cluster 1 (Figure 4). The main cause of mortality in this group was acute respiratory failure.

\section{Discussion}

In this sample, using the same statistical features to construct clusters and using clinical variables used in previous studies, we identified four different groups of COPD patients. The main finding was related to the cluster with higher values of peripheral eosinophils. It is the first time that patients with higher eosinophil values have been characterized in a single group of COPD patients. This result demonstrates the presence of different characteristics in a portion of Brazilian COPD patients evaluated compared to other cluster studies. ${ }^{4,11-13,23}$

Knowledge about the mechanism of eosinophil in COPD development is still scarce. ${ }^{35,36}$ The literature present different patterns of systemic and airway inflammation involving eosinophilic and non-eosinophilic COPD. ${ }^{35-37}$ However, the precise definition of the mechanisms associated with eosinophils has not yet been fully clarified. ${ }^{37,38,39}$ This cell is considered a biomarker to guide pharmacological treatment in patients with an increased risk of exacerbation. ${ }^{36,37}$ However, in the present study we did not identify association with increased rate of exacerbation in this cluster. On the other hand, the mean values considered in the literature are much lower than the values found in cluster 2. It demonstrates a specific COPD group with a different mechanism associated to present higher values of peripheral eosinophils. In comparison to the literature, most of them excluded COPD patients with $>600$ peripheral eosinophils. ${ }^{35,38}$ When we looked to asthma association, we did not observe a significant prevalence (4.3\%) associated in this group. The hypothesis that this group may have other diagnoses, not performed in this study, remains. Some diagnoses, such as intestinal parasitosis, can elevate the eosinophils values, which act on innate immune response against infections, due to their microbicidal function and their ability to act as antigen presenting cells and amplify the Th1 response. ${ }^{40,41}$ In Brazil, the number of incidences of intestinal parasitosis related to serum eosinophils is scare, a study with 66 garbage collectors showed eosinophils $>8 \%$ was $17 \%$ of the sample, and this number was not related to parasitosis. ${ }^{42}$

We observed that this eosinophil group presented the higher mean value of 6MWD with the same lung function parameters to other groups. This can be associated to the lower rate of the previous exacerbation rate. However, after 1 year of follow-up, we observed an increase in the exacerbation rate (Table 1) and an even higher proportion of

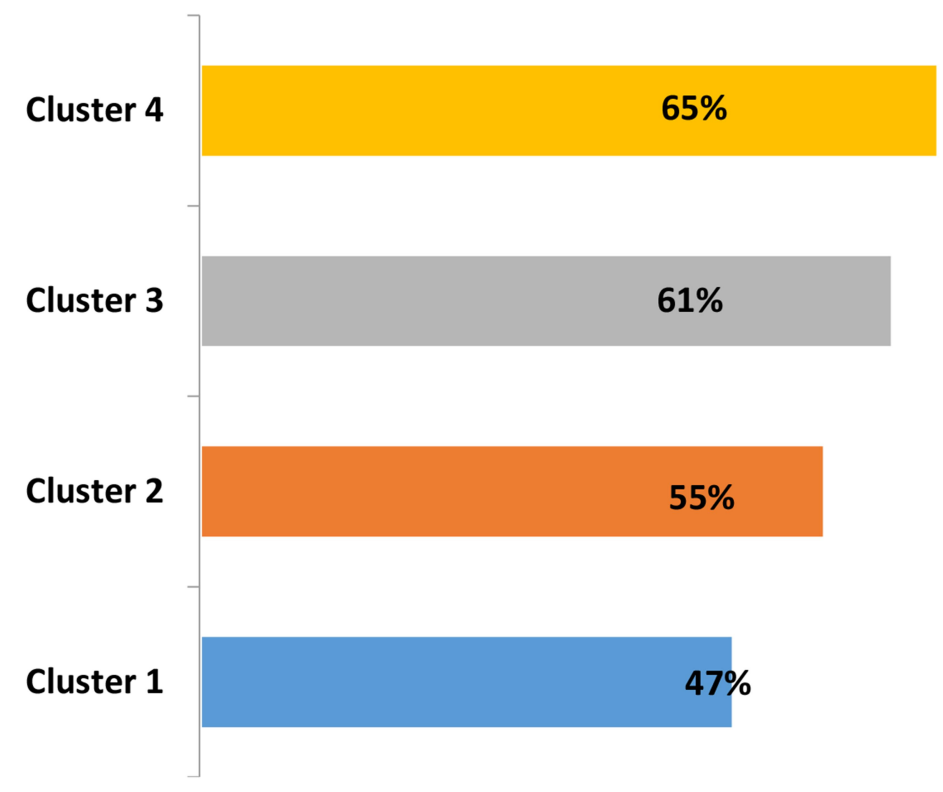

$p=0.273$

Figure 3 Exacerbation rate. Values expressed as a percentage. 


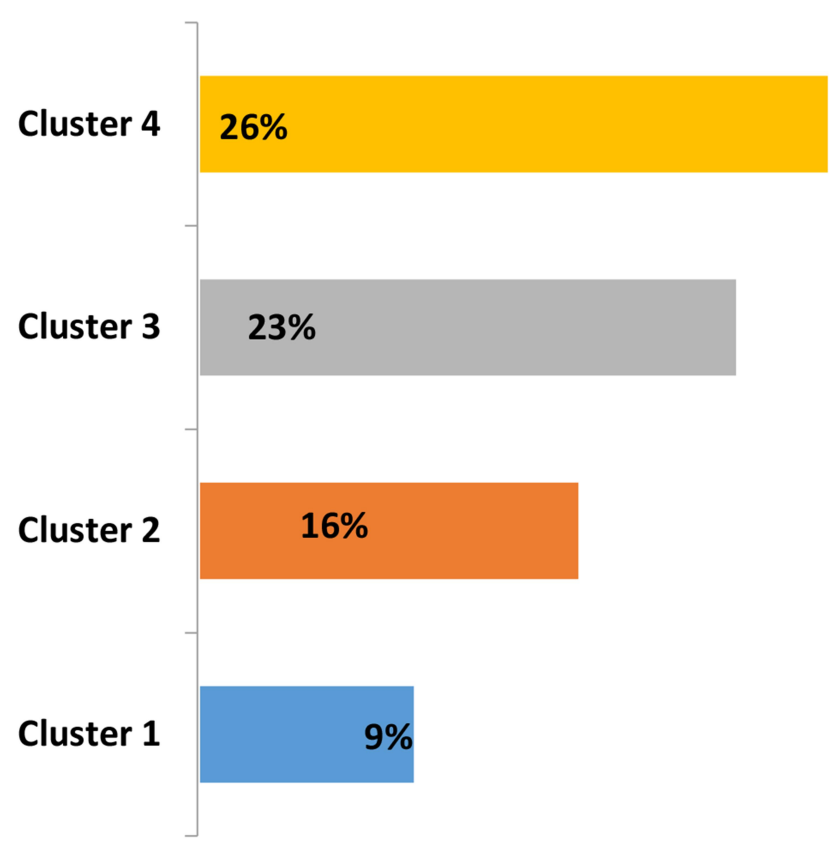

Figure 4 Mortality rate. Values expressed as a percentage.

patients who had been using inhaled corticosteroids $(68.2 \%)$. Although there is growing consensus that eosinophilia in COPD is a useful biomarker to evaluate the control of risk of exacerbations ${ }^{43}$ and response to inhaled corticosteroids, in the present study we did not observe an effective control in patients with elevated values of eosinophils. These controversial results related to this cluster can be related to a different mechanism associated to the response of the pharmacological treatment, that we cannot explain yet. We can speculate that those patients may respond better with antibody monoclonal treatments, such as anti-IL-5. ${ }^{43}$ There is evidence that eosinophils play a role in host adaptive response to viral pathogens and it has been observed that increased sputum eosinophilia during COPD exacerbations is related to viral loads. This may suggest that the mechanisms of eosinophilic inflammation in COPD may be a response to mainly viral infection, recruited by RANTES and without IL-5 involvement. ${ }^{40,41,43}$ Further studies need to evaluate the prevalence of this subgroup of COPD patients and the control of exacerbation rates.

The largest cluster in the present study was the cluster of patients that did not have any clinically important parameters to classify into cachexia, chronic respiratory failure, or eosinophilic. They presented lower impact on the BODE index, lower exacerbation, and lower mortality rate. Although these patients do not present differences in smoking, it is observed that they are active smokers because they do not have respiratory symptoms and they have lung function to lose. ${ }^{44,45}$ The literature shows that the evaluation of patients with mild COPD may detect different clusters, such as clusters with higher cigarette consumption and clusters with lower FEV1/FVC value. In this context, we can speculate that we can identify different clusters inside the largest cluster in our study, and the probability of random differences between the patient's characteristics of two centers included in this study. However, the outcomes of this cluster must be different to assess, like decline of lung function and cardiovascular outcomes. This cluster presented the higher proportion of metabolic comorbidities associated to COPD and can be related to higher risk of cardiovascular events. $^{46,47}$ In clinical practice, the identification of these patients should always be considered to receive appropriate treatment and better control of the disease. ${ }^{44,46,47}$

In the current study, cluster 3 identified high levels of CRP and neutrophils, with moderate airflow limitation, suggesting the association of the systemic inflammatory process and the systemic manifestation of disease (lower BMI values and lower physical performance). ${ }^{48,49}$ The literature is consistent to demonstrate an increased risk of mortality in COPD patients with cachexia. Those patients present a cyclic manifestation of impairment of quality-oflife associated to increased respiratory symptoms, that directly impacts exercise capacity and lower food ingestion. Consequently, those patients suffer with lower BMI that is difficult to control and treat. ${ }^{48-50}$

Finally, cluster 4 presented higher COPD severity, a lower $\mathrm{SpO}_{2}$ value, higher use of LTOT, higher BMI, and higher prevalence of associated OSAS. The severity of pulmonary obstruction associated with high BMI is related to worse quality-of-life and gas exchange. We also observed the higher proportion of mortality in this cluster associated to chronic respiratory failure. The literature is short with regard to the overlap syndrome, and the influence of different inflammatory markers in those patients is debated. ${ }^{8,10}$ Despite the occurrence of overlapping COPD showing evidence of the prevalence of morbidity and mortality, the prognostic factors that result in risk for exacerbations, hospitalizations, and mortality are still not accurate. ${ }^{51,52}$ Cell-mediated inflammation can trigger an important factor in the joint systemic inflammation pathways in COPD, OSAS, and cardiovascular diseases. The biological pathway is where neutrophils can influence the development of cardiovascular diseases and correlate with greater adhesion of platelets to subendothelial collagen, the release of leukotrienes, and increased oxidative 
stress and inflammatory mediators. ${ }^{52,53}$ The overlap syndrome with increased mortality rate can be related to mechanisms of chronic intermittent hypoxia that stimulates inflammatory cytokines and contributes to the increase in neutrophil overload, which can cause or worsen lung involvement in this patient ${ }^{53-56}$ and increased risk of acute exacerbation. ${ }^{57,58}$

The present study has limitations that need to be clarified. We cannot affirm that the characteristics of the identified clusters will not change if the sample is bigger or if we modify the clinical inclusion variables in the cluster analysis. Second, we did not evaluate the variation of the clinical characteristics during the follow-up of the study. Third, we cannot affirm the reproducibility of our results in different sample of COPD patients. Therefore, further studies are needed to confirm the results.

\section{Conclusion}

It was possible to identify four clinical different clusters in these COPD populations, that were related to different clinical manifestations, comorbidities, exacerbations, and mortality rate. Furthermore, a specific cluster with higher values of peripheral eosinophils was identified.

\section{Data Sharing Statement}

The data used to support the findings of this study are included within the article. No additional data are available.

\section{Ethics Approval and Consent to Participate}

This study protocol was approved by the Research Ethics Committee of the Clinical Hospital of Botucatu Medical School (approval number: 1399669 and CAAE: 52515215.2.1001.5411) and approved by the Brazilian Registry of Clinical Trials (REBEC) under the registration RBR-5B6B6S.

Written informed consent was obtained from each patient. If patients were unable to provide consent due to disease severity or other reasons, informed consent was obtained from relatives or a legal guardian.

\section{Consent to Publish}

All authors have read and approved the final manuscript.

\section{Author Contributions}

All authors made substantial contributions to the conception and design, acquisition of data, or analysis and interpretation of data; took part in drafting the article or revising it critically for important intellectual content; agreed to submit to the current journal; gave final approval of the version to be published; and agree to be accountable for all aspects of the work.

\section{Funding}

This work was supported by AstraZeneca Brazil through an investigator-initiated grant (ESR-15-10956).

\section{Disclosure}

José William Zucchi reports grants and subsidies from AstraZeneca Brazil for the study . The authors declare that they have no other potential conflicts of interest for this work.

\section{References}

1. Vogelmeier CF, Criner GJ, Martinez FJ, et al. Global strategy for the diagnosis. Management and prevention of chronic obstructive lung disease 2017 report. GOLD executive summary. Am J Respir Crit Care Med. 2017;195(5):557-582. doi:10.1164/rccm.201701-0218PP

2. Agusti A, Edwards LD, Rennard SI, et al. Persistent systemic inflammation is associated with poor clinical in COPD: a novel phenotype. PLoS One. 2012;7(5):e37483. doi:10.1371/journal.pone.0037483

3. Aksu F, Capan N, Aksu K, et al. C-reactive protein levels are raised in stable Chronic obstrutive pulmonar disease patients independent of smoking behavior and biomass exposure. $J$ Thorac Dis. 2013;5(4):414 421.

4. Burgel P-R, Paillasseur J-L, Janssens W, et al. A simple algorithm for the identificationof clinical COPD phenotypes. Eur Respir J. 2017;50:1701034.

5. Agusti A, Calverley PM, Celli B, et al. Characterisation of COPD heterogeneity in the ECLIPSE cohort. Respir Res. 2010;11:122. doi:10.1186/1465-9921-11-122

6. Chubachi S, Sato M, Kameyama N, et al. Identification of five clusters of comorbidities in a longitudinal Japanese chronic obstructive pulmonary disease cohort. Respir Med. 2016;117:272-279. doi:10.1016/j.rmed.2016.07.002

7. Laforest L, Roche N, Devouassoux G, et al. Frequency of comorbidities in chronic obstructive pulmonary disease. And impact on allcause mortality: a population-based cohort study. Respir Med. 2016;117:33-39. doi:10.1016/j.rmed.2016.05.019

8. Garcia-Aymerich J, Gomez FP, Benet M, et al. Identification and prospective validation of clinically relevant chronic obstructive pulmonary disease (COPD) subtypes. Thorax66. 2011;66(5):430-437. doi:10.1136/thx.2010.154484

9. Burgel P-R, Paillasseur J-L, Peene B, et al. Two distinct Chronic Obstructive Pulmonary Disease (COPD) phenotypes are associated with high risk of mortality. PLoS One. 2012;7(12):e51048. doi:10.1371/journal.pone. 0051048

10. Vanfleteren LE, Spruit MA, Groenen M, et al. Clusters of comorbidities based on validated objective measurements and systemic inflammation in patients with chronic obstructive pulmonary disease. Am J Respir Crit Care Med. 2013;187(7):728-735. doi:10.1164/rccm.201209-1665OC

11. Burgel PR, Paillasseur JL, Roche N. Identification of clinical phenotypes using cluster analyses in COPD patients with multiple comorbidities. Biomed Res Int. 2014;2014:420134. doi:10.1155/2014/420134

12. Rennard SI, Locantore N, Delafont B, et al. Identification of Five chronic obstructive pulmonary disease subgroups with different prognoses in the ECLIPSE cohort using cluster analysis. Ann Am Thorac Soc. 2015;12(3):303-312. doi:10.1513/AnnalsATS.201403-125OC 
13. Kim S, Lim MN, Hong Y, et al. A cluster analysis of chronic obstructive pulmonary disease in dusty areas cohort identified three subgroups. BMC Pulm Med. 2017;17:209. doi:10.1186/s12890-0170553-9

14. de Torres JP, Marin JM, Martinez-Gonzalez C, et al. The importance of symptoms in the longitudinal variability of clusters in COPD patients: a validation study. Respirology. 2017.

15. Pinto LM, Alghamdi M, Benedetti A, Zaihra T, Landry T, Bourbeau J. Derivation and validation of clinical phenotypes for COPD: a systematic review. Respiratory. 2015;16:50.

16. Pikoula M, Quint JK, Nissen F, et al. Identifying clinically important COPD subtypes using data-driven approaches in primary care population based electronic health records. BMC Med Inform Decis Mak. 2019;19:86. doi:10.1186/s12911-019-0805-0

17. Stockley RA. Biomarkers in chronic obstructive pulmonary disease: confusing or useful?. Int J Chron Obstr Pulm Dis. 2014;9:163-177. doi:10.2147/COPD.S42362

18. Faner R, Tal-Singer R, Riley JH, et al. Lessons from ECLIPSE: a review of COPD biomarkers. Thorax. 2014;69:666-672. doi:10.1136/ thoraxjnl-2013-204778

19. Barnes NC, Sharma R, Lettis S, et al. Blood eosinophils as a marker of response to inhaled corticosteroids in COPD. Eur Respir J. 2016;47:1299-1303. doi:10.1183/13993003.01370-2015

20. DiSantostefano RL, Hinds D, Van Le H, Barnes NC. Relationship between blood eosinophils and clinical characteristics in a crosssectional study of a US populationbased COPD cohort. Respir Med. 2016;112:88-96. doi:10.1016/j.rmed.2016.01.013

21. Schumann DM, Tamm M, Kostikas K, Stolz D. Stability of the blood eosinophilic phenotype in stable and exacerbated COPD. Chest. 2019;pii: S0012-3692(19)30878-5.

22. Castaldi PJ, Dy J, Ross J, et al. Cluster analysis in the COPDGene study identifies subtypes of smokers with distinct patterns of airway disease and emphysema. Thorax. 2014;69:415-422. doi:10.1136/ thoraxjnl-2013-203601

23. Guillamet RV, Ursu O, Iwamoto G, et al. Chronic obstructive pulmonar disease phenotypes using cluster analysis of electronic medical records. Health Informatics J. 2016;1-16.

24. Crapo RO, Enright PL, Zeballos RJ. ATS statement: guidelines for the six-minute walk test. Am J Respir Crit Care Med. 2002;166:111117.

25. GOLD. Global Initiative for Chronic Obstructive Lung Disease. Global Strategy for the Diagnosis, Management and Prevention of COPD; 2017.

26. Sociedade Brasileira de Pneumologia e Tisiologia (SBPT). II Consenso brasileiro sobre doença pulmonar obstrutiva crônica. $J$ Pneumol. 2004;30(5):S1-S42.

27. Schunemann HJ, Griffith L, Jaeschke R, Goldstein R, Stubbing D, Guyatt GH. Evaluation of the minimal important difference for the feeling thermo meter and the St. George's Respiratory Questionnaire in patients with chronic airflow obstruction. J Clin Epidemiol. 2003;56(12):1170-1176. doi:10.1016/S0895-4356(03) 00115-X

28. Jones PW, Harding G, Berry P, Wiklund I, Chen WH, Kline Leidy N. Development and first validation of the COPD assessment test. Eur Respir J. 2009;34(3):648-654. doi:10.1183/09031936.00102509

29. Marcolino JAM, Suzuki FM, Alli LAC, Gozzani JL, Mathias LAST. Medida da Ansiedade e da Depressão em Pacientes no PréOperatório. Estudo Comparativo. Rev Bras Anestesiol. 2007;57 (2):157-166. doi:10.1590/S0034-70942007000200004

30. Zigmond AS, Snaith RP. The hospital anxiety and depression scale. Acta Psychiatr Scand. 1983;67:361-370. doi:10.1111/j.16000447.1983.tb09716.x

31. Mahler DA, Weinberg DH, Wells CK, Feinstein AR. The measurement of dyspnea. Contents, interobserver agreement, and physiologic correlates of two new clinical indexes. Chest. 1984;85(6):751-758. doi:10.1378/chest.85.6.751
32. Celli BR, Cote CG, Marin JM, et al. The body-mass index, airflow obstruction, dyspnea, and exercise capacity index in chronic obstructive pulmonary disease. $N$ Engl J Med. 2004;350:1005-1012. doi:10.1056/NEJMoa021322

33. Diretrizes da Sociedade Brasileira de Diabetes 2017-2018/ Organização José Egídio Paulo de Oliveira, Renan Magalhães Montenegro Junior, Sérgio Vencio. São Paulo: Editora Clannad; 2017.

34. Faludi AA, Izar MCO, Saraiva JFK, et al. Atualização da diretriz brasileira de dislipidemias e prevenção da aterosclerose - 2017. Arq Bras Cardiol. 2017;109:1. doi:10.5935/abc.20170121

35. Magnussen H, Disse B, Rodriguez-Roisin R, et al.; WISDOM Investigators. Withdrawal of inhaled glucocorticoids and exacerbations of COPD. New Engl J Med. 2014;371(14):1285-1294. doi:10.1056/NEJMoa1407154.

36. Roche N, Vogelmeier CF, Herth FJ, et al. Blood eosinophils and response to maintenance COPD treatment: data from the FLAME trial. Am J Respir Crit Care Med. 2017;195:1189-1197. doi:10.1164/ rccm.201701-01930C

37. Saetta M, Di Stefano A, Maestrelli P, et al. Airway eosinophilia in chronic bronchitis during exacerbations. Am J Respir Crit Care Med. 1994;150:1646-1652. doi:10.1164/ajrccm.150.6.7952628

38. Ravin KA, Loy M. The eosinophil in infection. Clin Rev Allergy Immunol. 2016;50:214-227. doi:10.1007/s12016-015-8525-4

39. Liao W, Long H, Chang CC, Lu Q. The eosinophil in health and disease: from bench to bedside and back. Clin Rev Allergy Immunol. 2016;50:125-139. doi:10.1007/s12016-015-8507-6

40. Suissa S, Dell'Aniello S, Ernst P. Comparative e ectiveness and safety of LABA-LAMA vs LABA-ICStreatment of COPD in realworld clinical practice. Chest. 2019;155:1158-1165. doi:10.1016/j. chest.2019.03.005

41. Wedzicha JA. Eosinophils as biomarkers of chronic obstructive pulmonary disease exacerbation risk. Maybe just for some? Am J Respir Crit Care Med. 2016;193:937-938. doi:10.1164/rccm.201601-0015ED

42. Júnior MGH, Cardoso WM, Weis SMS, et al. Intestinal parasitism among waste pickers in Mato Grosso do Sul, Midwest Brazil. Rev Inst Med Trop São Paulo. 2017;59:e87.

43. Turato G, Semenzato U, Bazzan E, et al. Blood eosinophilia neither reflects tissue eosinophils nor worsens clinical outcomes in chronicobstructive pulmonary disease. Am J Respir Crit Care Med. 2018;197:1216-1219. doi:10.1164/rccm.201708-1684LE

44. Tinè $\mathrm{T}$, Biondini $\mathrm{B}$, Semenzato $\mathrm{S}$, et al. Reassessing the role of eosinophils as a biomarker in chronic obstructive pulmonary disease.J Clin Med. 2019;8(7):962. doi:10.3390/jcm8070962

45. Papi A, Bellettato CM, Braccioni F, et al. Infections and airway inflammation in chronic obstructive pulmonary disease severe exacerbations. Am J Respir Crit Care Med. 2006;173:1114-1121. doi:10.1164/rccm.200506-8590C

46. de Oliveira Caram LM, Ferrari R, Naves CR, et al. Risk factors for cardiovascular disease in patients with COPD: mild-to-moderate COPD versus severe-to-very severe COPD. J Bras Pneumol. 2016;42(3):179-184. doi:10.1590/S1806-37562015000000121

47. Leong P, Macdonald MI, Ko BS, Bardin PG. Coexisting chronic obstructive pulmonary disease and cardiovascular disease in clinical practice: a diagnostic and therapeutic challenge. Med J Aust. 2019;210(9):417-423. doi:10.5694/mja2.50120

48. Merry-Lynn N, McDonald EF, Wouters M, et al. It's more than low BMI: prevalence of cachexia and associated mortality in COPD. Respir Res. 2019;20:100. doi:10.1186/s12931-019-1073-3

49. Bhatt SP, Soler X, Wang X, et al. Association between functional small airway disease and FEV1 decline in chronic obstructive pulmonary disease. Am J Respir Crit Care Med. 2016;194(2):178-184. doi:10.1164/rccm.201511-2219OC

50. Mesquita R, Spina G, Pitta F, et al. Physical activity patterns and clusters in 1001 patients with COPD. Chron Respir Dis. 2016. 
51. McNicholas WT. Chronic obstructive pulmonary disease and obstructive sleep apnoea: the overlap syndrome. J Thorac Dis. 2016;8 (2):236-242.

52. Gao J, Iwamoto H, Koskela J, et al. Characterization of sputum biomarkers for asthma-COPD overlap syndrome. Int J Chron Obstruct Pulmon Dis. 2016;11:2457-2465. doi:10.2147/COPD. S113484

53. Paplinska-Goryca M, Nejman-Gryz P, Gorska K, Bialek-Gosk K, Hermanowicz-Salamon J, Krenke R. Expression of inflammatory mediators in induced sputum: comparative study in asthma and COPD. Adv Exp Med Biol. 2016.

54. Cosio BG, Soriano JB, Lopez-Campos JL, et al. Defining the asthmaCOPD overlap syndrome in a COPD cohort. Chest. 2016;149:45-52. doi:10.1378/chest. $15-1055$
55. Alshabanat A, Zafari Z, Albanyan O, et al. Asthma and COPD overlap syndrome (ACOS): a systematic review and meta analysis. PLoS One. 2015;10:e0136065. doi:10.1371/journal.pone.0136065

56. Perez de Llano L, Cosio BG, Miravitlles M, et al. Accuracy of a new algorithm to identify asthmaCOPD overlap (ACO) patients in a cohort of patients with chronic obstructive airway disease. Arch Bronconeumol. 2018;54:198-204. doi:10.1016/j.arbres.2017.10.007

57. Kobayashi S, Hanagama M, Yamanda S, Ishida M, Yanai M. Inflammatory biomarkers in asthmaCOPD overlap syndrome. Int $J$ Chron Obstruct Pulmon Dis. 2016;11:2117-2123. doi:10.2147/ COPD.S113647

58. van Boven JF, Roman-Rodriguez M, Palmer JF, et al. Comorbidome, pattern and impact of asthma-COPD overlap syndrome (ACOS) in reallife. Chest. 2016;149:1011-1020. doi:10.1016/j.chest.2015.12.002

International Journal of Chronic Obstructive Pulmonary Disease

\section{Publish your work in this journal}

The International Journal of COPD is an international, peer-reviewed journal of therapeutics and pharmacology focusing on concise rapid reporting of clinical studies and reviews in COPD. Special focus is given to the pathophysiological processes underlying the disease, intervention programs, patient focused education, and self management protocols. This journal is indexed on PubMed Central, MedLine and CAS. The manuscript management system is completely online and includes a very quick and fair peer-review system, which is all easy to use. Visit http://www.dovepress.com/testimonials.php to read real quotes from published authors. 